\title{
Late adolescents' perception of their peers who report a large number of sex partners
}

\author{
Seojin Choi, Dong-ouk Yang, Gahyun Youn* \\ Department of Psychology, Chonnam National University, 77 Yongbong, Gwangju, Korea
}

Email address:

ghyoun@chonnam.ac.kr (G. Youn)

To cite this article:

Seojin Choi, Dong-ouk Yang, Gahyun Youn. Late Adolescents' Perception of their Peers Who Report a Large Number of Sex Partners. Psychology and Behavioral Sciences. Vol. 4, No. 1, 2015, pp. 1-4. doi: 10.11648/j.pbs.20150401.11

\begin{abstract}
What is the reason for gender discrepancy in reporting lifetime sex partners (SPs) when people are asked for the number of SPs they have had? Based on the idea of the sexual double standard, men might over-report while women might under-report the number of SPs. The purpose of this study was to identify whether this gender discrepancy could be explained by the sexual double standard or not. Late adolescents were asked to report the number of their lifetime SPs and to assess how they perceive sexual behaviors of an imaginary peer who reports a large number of SPs. Data were collected through a one-toone interview sessions (over 90\% of the sample). The lifetime number of SPs for men was almost 6 times higher than that for women. Men showed more envious attitudes and assessed the peer's report as less factual when the peer man had more SPs. Women were not willing to accept the man as their prospective partner if he had many SPs. Also, the sexual behavior of the peer woman with many SPs was deemed undesirable by women. The findings imply that men might inflate their reports of the number of lifetime SPs, supporting the old sexual double standard. The findings also imply that women might under-report their lifetime SPs, and seemed to be somewhat ambivalent about the topic of the sexual double standard.
\end{abstract}

Keywords: Sexual Double Standard, Sex Partner, Casual Sex, Over-Reporting, Under-Reporting

\section{Introduction}

In population-based surveys on sexual behavior, heterosexual men and women should theoretically report the same number of sex partners (SPs) when they are asked for the number of SPs they have had so far [1,2]. However, men were shown to consistently report a greater number of SPs than women do in most studies [3,4]. Men are more approving of casual sex, more inclined to engage in sexual behavior outside of committed relationships, and report a higher incidence of intercourse than women. On the contrary, women report more sexual caution and are more discriminating with regard to quality and quantity of SPs than men $[5,6]$.

What is the reason for such gender discrepancy in reporting SPs? Sociobiologists may account for this discrepancy by addressing the existence of the double standard, that is, more permissive attitudes towards male promiscuity and greater intolerance for female promiscuity by society. Thus, men should be more approving of casual sex and should have a larger number of different SPs, whereas women should be less approving of casual sex and should have a smaller number of different SPs [6].

In terms of social learning, the double standard indicates that women are punished for sexual activities such as having numerous SPs or engaging in casual sex, whereas men are not likely to be punished, or may even be rewarded (through admiration or increased social status) for such behaviors. Therefore, social learning theory predicts a lower average number of SPs for women than for men. Compared to women, men are significantly more likely to report having had several partners, and less likely to report no SPs or only one $[5,6]$. The theory also predicts that women will hold more negative attitudes about casual sex than men [6].

The discrepancy is also explained by social role or script theory. Sexual behaviors are governed by gender roles and scripts or gender-typed expectations [6]. Many people still accept some forms of the sexual double standard, in which men are afforded more sexual freedom than women, and women are expected to be more reluctant than men to acknowledge their desire for sex [7, 8]. Women and men can anticipate different consequences when their behaviors are 
deviated from prescribed behaviors: Men are likely to find their sexual potential questioned, while women risk being "deviants," "criminals," "sluts," or "whores." As a result, men may be motivated to be approving of sexual behaviors and to exaggerate the frequency and variability of their sexual encounters, whereas women may be motivated to understate it [9-11].

No matter what theory is used to explain such phenomenon, the discrepancy can be explained by the sexual double standard. Sexual intercourse outside marriage was acceptable for men but not for women according to the old, traditional double standard, whereas sex outside of marriage is somewhat tolerated for both men and women according to a new, conditional double standard [12]. With this in mind, the question is now concerned with the extent of the idea of the double standard followed by young people of today. Knowing the answer to this question would be helpful in predicting the sexual behavior of young people. Thus, in this study, late adolescents were asked to report the number of their lifetime SPs as well as to assess how they perceive sexual behaviors of an imaginary peer who reports a large number of premarital casual SPs.

\section{Methods}

\subsection{Participant Recruitment and Data Collection}

Participants included 227 men aged 18.6 to 28.9 years $(M=23.6, S D=2.6)$ and 204 women aged 18.4 to 28.7 years $(M=22.5, S D=2.8)$. They all were heterosexual, never married, and volunteers who were not reluctant to take a sex survey. They responded to the measures anonymously either in small, same-sex groups of 2 to 5 (less than $10 \%$ of the sample), or through a one-to-one interview (over $90 \%$ of the sample). The purpose of the study was explained and verbal consent was obtained prior to the interview. Data were collected during the period from early 2011 to early 2012 in Korea.

\subsection{Measures}

Eighteen items [9 items on enviousness and 9 items on factualness of the sexual behavior of an imaginary man (IM)] were asked to men. A sample item on enviousness (factualness) was "If a 27-year-old unmarried IM reported having had 50 SPs so far, I am envious of him (and I believe his report)." The IM's age of 27 in the item was replaced with 23 or 19 in the other items, and the SPs' number of 50 was also replaced with 20 or 10 in the other items.

Twenty-one items [9 items on acceptance of the sexual behavior of an IM, and 12 items on desirability of the sexual behavior of an imaginary woman (IW)] were asked to women. A sample item on acceptance was "If a 27-year-old unmarried IM reported having had 50 SPs initiated a date, I would like to accept him as my prospective dating partner." A sample item on desirability was "If a 27-year-old unmarried IW reported having had 50 SPs so far, I consider her sexual activity desirable. The IW's age of 27 in the item was replaced with 23 or 19 in the other items, and the SPs' number of 50 was also replaced with 20,10 or 0 in the other items.

The responses to all the above-mentioned items for both genders were rated on an 11-point Likert scale ranging from 0 (strongly disagree) to 10 (strongly agree).

All respondents were asked to report the number of their total lifetime SPs.

\section{Results}

\subsection{Self-Reported Number of SPS}

The reported lifetime SPs are shown in the Table 1. Only 9 (4.4\%) women and $19(8.4 \%)$ men did not respond to the question on lifetime SPs. Above all, age was not associated with the number of SPs among men $[r(208)=0.19, p>.05]$, but was strongly associated among women $[r(195)=0.51, p<.01]$. Overall, men $($ Mean=10.3, Median=4.0, Range $=0-145)$ reported substantially more SPs than women (Mean=1.7, Median=1, Range $=0-14$ ). About $23.1 \%$ of men reported no SP, while about $49.7 \%$ of women did. Almost $28 \%$ of men reported 10 or more lifetime SPs, compared with slightly over $2 \%$ of women.

Table 1. Number of reported lifetime SPs by gender

\begin{tabular}{lll}
\hline No. of SPs & Men $(\boldsymbol{N}=\mathbf{2 0 8 *})$ & Women $(\boldsymbol{N = 1 9 5 *})$ \\
\hline None & $48(23.1 \%)$ & $97(49.7 \%)$ \\
1 & $17(8.2 \%)$ & $31(15.9 \%)$ \\
$2-3$ & $35(16.8 \%)$ & $38(19.5 \%)$ \\
$4-5$ & $22(10.6 \%)$ & $12(6.2 \%)$ \\
$6-9$ & $28(13.5 \%)$ & $13(6.7 \%)$ \\
$10-19$ & $31(14.9 \%)$ & $4(2.1 \%)$ \\
$20+$ & $27(13.0 \%)$ & 0 \\
\hline
\end{tabular}

* 19 men and 9 women did not respond.

\subsection{Men's Enviousness and Factualness}

The mean ratings for enviousness and factualness are presented in Table 2. The ratings of the 9 items on enviousness were entered simultaneously into a $3 \times 3$ repeated measures ANOVA (i.e., 3 ages of IM by 3 numbers of SPs design). The ANOVA showed a significant main effect of SPs' number $[F(2,450)=12.51, p<.001]$, and a follow-up analysis showed a linear trend $[F(1,225)=18.23, p<.001]$, indicating that greater enviousness was felt to toward men with a greater number of SPs. The ANOVA also showed a significant main effect of the IM's age, $F(2,450)=3.12, p<.05$, but no linear function, $F(1,225)=3.00, p>.05$. No significant interaction between the SPs' number and IM's age was observed $[F(4,900)=1.53$, n.s. $]$.

The ratings of the 9 items on factualness were also entered into a $3 \times 3$ repeated measures ANOVA (i.e., 3 ages of IM by 3 numbers of SPs design). The ANOVA showed a significant main effect of SPs' number $[F(2,448)=61.23, p<.001]$, and a 
linear trend in the follow-up analysis $[F(1,224)=93.32$, $p<.001]$. The ANOVA also showed a significant main effect of the IM's age $[F(2,448)=210.71, p<.001]$ with a linear trend in the follow-up analysis $[F(1,224)=226.22, p<.001]$. That is, the participants perceived the IM's report as more factual when the IM reported less SPs and when the IM's age was younger. A significant interaction between the SPs' number and IM's age was observed $[F(4,896)=3.33, p<.05]$, but interpretation of the effect of interaction was inadequate for the purpose of this study.

Table 2. Statistics for enviousness and factualness [M (SD)]

\begin{tabular}{llccc}
\hline \multirow{2}{*}{ Measure } & \multirow{2}{*}{ IM's age } & \multicolumn{3}{c}{ Number of SPs } \\
\cline { 3 - 5 } & & $\mathbf{1 0}$ & $\mathbf{2 0}$ & $\mathbf{5 0}$ \\
\hline \multirow{4}{*}{ Enviousness } & $19 \mathrm{yrs}$ & $3.45(3.51)$ & $3.82(3.69)$ & $4.20(3.89)$ \\
& $23 \mathrm{yrs}$ & $3.74(3.06)$ & $4.13(3.22)$ & $4.50(3.45)$ \\
& $27 \mathrm{yrs}$ & $3.93(3.34)$ & $4.26(3.39)$ & $4.37(3.55)$ \\
& $19 \mathrm{yrs}$ & $3.90(3.12)$ & $2.92(2.91)$ & $2.35(2.82)$ \\
Factualness & $23 \mathrm{yrs}$ & $5.57(2.74)$ & $4.68(2.76)$ & $3.85(2.53)$ \\
& $27 \mathrm{yrs}$ & $6.56(3.09)$ & $6.02(3.04)$ & $5.30(2.95)$ \\
\hline
\end{tabular}

Note. Response range: 0 (strongly disagree) to 10 (strongly agree).

\subsection{Women's Acceptance and Desirability}

The mean ratings for acceptance are presented in Table 3. The ratings of the 9 items on acceptance were entered simultaneously into a $3 \times 3$ repeated measures ANOVA (i.e., 3 ages of IM by 3 numbers of SPs design). The ANOVA showed a significant main effect of SPs' number $[F(2,406)=82.13, p<.001]$, and a follow-up analysis showed a linear trend $[F(1,203)=101.16, p<.001]$, indicating a greater acceptance of a man with less SPs as a prospective partner. The ANOVA also showed a significant main effect of the IM's age, $F(2,406)=144.99, p<.001$, with a linear trend in the follow-up analysis, $F(1,203)=198.60, p<.001$, showing less acceptance of the IM as a partner with younger age. A significant interaction between the SPs' number and IM's age emerged $[F(4,812)=44.89, p<.001]$, but interpretation of the effect of interaction was inadequate for the purpose of this study.

Table 3. Statistics for acceptance [M (SD)]

\begin{tabular}{lccc}
\hline \multirow{2}{*}{ IM's age } & \multicolumn{3}{c}{ Number of SPs } \\
\cline { 2 - 4 } & $\mathbf{1 0}$ & $\mathbf{2 0}$ & $\mathbf{5 0}$ \\
\hline $19 \mathrm{yrs}$ & $0.65(1.56)$ & $0.48(1.21)$ & $0.41(1.21)$ \\
$23 \mathrm{yrs}$ & $2.34(2.48)$ & $1.68(2.19)$ & $1.40(2.19)$ \\
$27 \mathrm{yrs}$ & $3.74(2.97)$ & $2.55(2.59)$ & $1.92(2.48)$ \\
\hline
\end{tabular}

Note. Response range: 0 (strongly disagree) to 10 (strongly agree).

The mean ratings for desirability are presented in Table 4. The ratings of the 12 items on desirability were entered simultaneously into a 3x4 repeated measures ANOVA (i.e., 3 ages of IW by 4 numbers of SPs design). The ANOVA revealed significant main effects of both SPs' number
$[F(3,609)=495.22, \quad p<.001] \quad$ and the IW's age $[F(2,406)=89.36, \quad p<.001]$, with a significant interaction effect $[F(6,1218)=259.55, \quad p<.001]$. For the interaction, analyses of simple effects on the IW's age revealed that a linear trend was appropriate for the IW's age 27 $[F(1,203)=174.44, p<.001]$ while quadratic trends were better for the IW's age $23[F(1,203)=154.50, p<.001]$ and 19 $[F(1,203)=1201.62, p<.001]$.

For the interaction, analyses of simple effects for number of SPs revealed that linear trends were shown for four conditions of SPs' number but implied different meanings. As for the three conditions of 50,20, and $10 \mathrm{SPs}$, the female participants perceives that the younger the IW is, the less desirable the IW is $[F(1,203)=121.35, p<.001$ for $50 \mathrm{SPs}$; $F(1,203)=221.85, \quad p<.001$ for 20 SPs; $F(1,203)=367.99$, $p<.001$ for $10 \mathrm{SPs}$. However, they perceived that the older the IW is, the less desirable the IW is, as for the 0 SP condition $[F(1,203)=223.08, p<.001]$.

Table 4. Statistics for desirability [M (SD)]

\begin{tabular}{lcccc}
\hline \multirow{2}{*}{ IM's age } & \multicolumn{4}{c}{ Number of SPs } \\
\cline { 2 - 5 } & $\mathbf{0}$ & $\mathbf{1 0}$ & $\mathbf{2 0}$ & $\mathbf{5 0}$ \\
\hline $19 \mathrm{yrs}$ & $8.69(2.56)$ & $0.50(1.30)$ & $0.32(1.00)$ & $0.23(0.89)$ \\
$23 \mathrm{yrs}$ & $6.94(2.71)$ & $2.46(2.21)$ & $1.57(1.96)$ & $1.08(1.77)$ \\
$27 \mathrm{yrs}$ & $5.39(3.03)$ & $4.17(2.83)$ & $2.80(2.63)$ & $1.83(2.33)$ \\
\hline
\end{tabular}

Note. Response range: 0 (strongly disagree) to 10 (strongly agree).

\section{Discussion}

This study asked late adolescents to report their lifetime number of SPs as well as to assess sexual behaviors of an imaginary person. Participants in this study were volunteers who were not reluctant to participate in a sex survey, and thus they might have had more SPs than those who did not participate. Nevertheless, the reported number of lifetime SPs for men $(M=10.3)$ was almost six times higher than that for women $(M=1.7)$. What may be a possible explanation for such large discrepancy?

First, let's look at the response patterns of men. Male participants showed more envious attitudes toward the IM (imaginary man) with more SPs. At the same time, they thought that the IM's report on the number of SPs was less factual when the IM had more SPs. These findings imply that male participants might inflate their reports when they are asked to report the number of lifetime SPs. The findings also suggest that male participants would still follow the idea of the old sexual double standard.

On the other hand, the response patterns of women were different. They were not willing to accept the IM as their prospective dating partner if he has had many SPs. In general, they showed less acceptance for the IM who was younger and who has had more SPs. Contrary to the favorable response received by male participants, the IM with many SPs was in disfavor with female participants. Then, how did the female participants respond to the sexual behavior of the 
IW (imaginary woman) who reported as having had many SPs? They in general assessed the sexual behavior of the IW as undesirable, but there were big differences in their assessment of desirability depending on the IW's age. They assessed the younger IW as a more undesirable person. For instance, female participants assessed the sexual behavior of the 27-year-old IW with 10 SPs as somewhat neutral, although the mean number of their reported lifetime SPs was only 1.7. This kind of response pattern was more conspicuous when they responded to the IW with no SP. They assessed her as almost neutral when the IW was 27 years old, while they assessed her as quite desirable when the IW was 19 years old.

Almost half of the female participants reported their SPs as none, but many women assessed the IW with no SP as undesirable. This means that women might under-report their lifetime SPs in this study. On the basis of the old double standard, females should show negative attitudes toward women's premarital sex. However, as gender roles have changed since the second half of the $20^{\text {th }}$ century, the gender standard has been also changing over time [3]. The findings from the female participants imply that they are not complying with the old double sexual standard but they are with the new one.

In conclusion, the young generation in Korea might still follow the idea of the double standard. Although there have been changes in the gender roles or gender-typed expectations since the late $20^{\text {th }}$ century, young men in Korea still comply with the old sexual double standard. Therefore, they could not conceal their envy of the person with many SPs. For this reason, they are likely to inflate their reports on the number of SPs because men who have many SPs had been traditionally treated as great persons, even though the reported values were often assessed as untrue. However, women seemed to be somewhat ambivalent on the double standard. Some women followed the old sexual double standard and thus assessed the woman with many SPs as undesirable, while some other women followed the new double standard and thus assessed the woman with no SP as undesirable. Nevertheless, women were assumed to underreport the number of their lifetime SPs.

\section{References}

[1] Brown, N., \& Sinclair, R. (1999). Estimating number of lifetime sexual partners: Men and women do it differently. Journal of Sex Research, 36, 292-297.

[2] Pedersen, W., Miller, L., Putcha-Bhagavatula, A., \& Yang, Y. (2002). Evolved sex differences in the number of partners desired? The long and the short of it. Psychological Science, $13(2), 157-161$.

[3] Hyde, J., \& Oliver, M. (2000). Gender differences in sexuality: Results from a meta-analysis. In C. Tavris \& J. White (Eds.), Sexuality, society, and feminism (pp. 57-77). Washington, DC: American Psychological Association.

[4] Nnko, S., Boerma, J., Urassa, M., Mwaluko, G., \& Zaba, B. (2004). Secretive females or swaggering males? An assessment of the quality of sexual partnership reporting in rural Tanzania. Social Science \& Medicine, 59, 299-310.

[5] Laumann, E., Gagnon, J., Michael, R., \& Michaels, S. (1994). The social organization of sexuality: Sexual practices in the United States. Chicago: University of Chicago Press.

[6] Oliver, M., \& Hyde, J. (1993). Gender differences in sexuality: A meta-analysis. Psychological Bulletin, 114, 29-51.

[7] Gentry, M. (1998). The sexual double standard: The influence of number of relationships and level of sexual activity on judgments of women and men. Psychology of Women Quarterly, 22, 505-511.

[8] Kreager, D., \& Staff, J. (2009). The sexual double standard and adolescent peer acceptance. Social Psychology Quarterly, 72 (2), 143-164.

[9] Alexander, M., \& Fisher, T. (2003). Truth and consequences: Using the bogus pipeline to examine sex differences in selfreported sexuality. Journal of Sex Research, 40, 27-35.

[10] Brody, S. (1997). Sex at Risk. London: Transaction Publishers.

[11] King, J. (2005). The Victorian woman question in contemporary feminist fiction. New York: Palgrave Macmillan.

[12] Sprecher, S., McKinney, K., \& Orbuch, T. (1987). Has the double standard disappeared? An experiment test. Social Psychology Quarterly, 50, 24-31. 